\title{
Real Jurors' Understanding of the Law in Real Cases*
}

\author{
Alan Reifman, Spencer M. Gusick, and \\ Phoebe C. Ellsworth $\dagger$
}

A survey of 224 Michigan citizens called for jury duty over a 2-month period was conducted to assess the jurors' comprehension of the law they had been given in the judges' instructions. Citizens who served as jurors were compared with a base line of those who were called for duty but not selected to serve, and with those who served on different kinds of cases. Consistent with previous studies of mock jurors, this study found that actual jurors understand fewer than half of the instructions they receive at trial. Subjects who received judges' instructions performed significantly better than uninstructed subjects on questions about the procedural law, but no better on questions about the substantive (criminal) law. Additionaliy, jurors who asked for help from the judge understood the instructions better than other jurors. Since the results replicate previous research using simulated trials, this study provides evidence for the generalizability of earlier work to actual trials.

The belief that juries in most cases apply the relevant law correctly to the facts in reaching their verdicts has been referred to as an "invariable assumption of the law" (Richardson v. Marsh, 1987). Appellate court judges routinely endorse the idea that juries understand the instructions, and appeals based on juries' mistaken

\footnotetext{
* This study would not have been possible without the cooperation and assistance of the judges, administration, and jurors of the Twenty-Second Circuit Court of Michigan, in Ann Arbor. Special thanks to Judge William Ager, James Inloes, David Walsh, and Corey Peña for their extensive efforts in facilitating this research. We are also indebted to Judges Patrick Conlin, Ross Campbell, William Ager, Edward Deake, and Melinda Morris for allowing us to send questionnaires to their jurors. Judge Ager and Samuel Gross made helpful comments on an earlier draft of the manuscript. We are grateful to Daniel Weintraub, of the University of Michigan Psychology Honors Program for his guidance, and to Nancy Exelby for her superior skill and boundless patience. Spencer Gusick is now at the University of Michigan Law School. Alan Reifman is at the Research Institute on Alcoholism, 1021 Main Street, Buffalo, NY 14203. Requests for reprints should be sent to Phoebe C. Ellsworth, Research Center for Group Dynamics, University of Michigan, P.O. Box 1248, Ann Arbor, MI 48106.

$\dagger$ University of Michigan.
} 
interpretation of the law are rarely successful (Parker v. Randolph, 1979; City of Los Angeles v. Heller, 1986; United States v. Lane, n. 13, 1986; Martin v. Ohio, 1987). The appellate bench, however, may be the only place where this invariable assumption is widely expressed.

Among social scientists who have studied jury decision making the opposite assumption prevails: Jurors may be quite competent at sorting out the facts, but they have a very difficult time understanding the judge's instructions and often miss crucial distinctions. Study after study has shown that jurors do not understand the law they are given, often performing at no better than chance level on objective tests of comprehension (Charrow \& Charrow, 1979; Elwork, Sales, \& Alfini, 1977, 1982; Ellsworth, 1989; Forston, 1975; Hastie, Penrod, \& Pennington, 1983; Kaplan \& Kemmerick, 1974; Kassin \& Wrightsman, 1979; Kerr et al., 1976; Severance \& Loftus, 1982; Smith, 1987). Ellsworth (1989) found that although subject-jurors spent over $20 \%$ of their deliberation time discussing the law, only about half of their statements were correct, and one fifth were seriously in error. Nor did the juries show much progress toward the correct interpretation of the instructions over the course of the deliberation. Although some jurors' mistakes were corrected by other jurors, an equal number of correct statements about the law were abandoned in favor of mistaken ones. The same jurors were generally quite competent in their discussions of the facts; their confusion was specific to their attempts to define and apply the law.

Several reasons for this poor performance have been suggested. The most obvious is the legal language itself (Charrow \& Charrow, 1979; Elwork et al., 1982). Rewriting judicial instructions with more conventional vocabulary and sentence structure can significantly increase jurors' recall of the law (Charrow \& Charrow, 1979; Elwork et al., 1977; Severance \& Loftus, 1982). Even when the language is simplified, however, accuracy is far from perfect, indicating that the convoluted legal language is not the only obstacle to comprehension.

Typically, jurors receive their education in the law by listening to the judge read the instructions aloud-far from the ideal way to absorb complex information. Some states currently require the inclusion of written instructions, while other states specifically prohibit them. In most states, it is up to the trial judge to decide whether or not to provide written instructions. The argument is that the judge is in the best position to determine what form of instructions is most appropriate for the particular case at hand, but in practice most judges either give written instructions all the time, or they do not give them at all.

There is very little research on the consequences of supplementing the oral instructions with a written copy, and the results are mixed. Although jurors seem to like the innovation and feel that it helps them understand, the evidence that it actually does so is weak (Forston, 1975; Hastie, 1983; Heuer \& Penrod, 1989).

Another source of poor juror comprehension of the law may be the timing of the instructions. Although attorneys may make piecemeal reference to the law during the trial, it is not until the conclusion of the trial-after the testimony of all the witnesses and the closing statements of the attorneys-that the judge systematically instructs the jurors in the substantive law. Smith (1987) found that jurors 
who were given both pretrial and posttrial instructions had significantly greater comprehension of the judges' instructions for the substantive law and were better able to apply their knowledge to the facts of a case than were subjects who received pretrial or posttrial instructions only.

Still another possible shortcoming of current practice is that jurors are rarely told that they are allowed to request help from the judge if they have a question about the law; thus it may not occur to them to ask for guidance when they need it. Even if a jury does request help, such "help" commonly takes the form of a verbatim repetition of the confusing instructions. Empirical research on this question is nonexistent; we do not know whether subjects do better when they are told that they can ask for help, nor do we know which kind of help (repetition, provision of written instructions, restatement, etc.) is most beneficial.

Although empirical research has consistently indicated that jurors have trouble comprehending the law presented at trials, and seems to have defined some of the sources of these difficulties, few changes have been introduced in the way judges instruct juries. Even when appellate courts have cited the research on juror comprehension of judges' instructions, they have consistently held that reform was unnecessary. If anything, recent judicial opinions have been more likely to change the rules governing instructions in ways contrary to the research findings than in ways consistent with them, such as prohibiting written instructions in jurisdictions where they were formerly permitted (Tanford, 1991). Legislatures, state agencies, and special commissions have been somewhat more receptive to research-based reform, but still, movement has been glacial (Tanford, 1991).

Although rapid implementation of social science findings is hardly the norm in the legal system (cf. Ellsworth \& Getman, 1987), in some ways the lack of impact of research on juror comprehension of the law is surprising. The basic issue is not politically controversial: no one is arguing that mistaken applications of the law are desirable. The proposed reforms are relatively simple, and neither researchers nor judges who have tried them have reported any negative consequences (cf. Sand \& Reiss, 1985).

One reason for this apathy may be that legal policymakers do not trust the research. Judges may be particularly skeptical of social science research that attempts to simulate what judges do or what happens in a real courtroom. They may be reluctant to consider the possibility that the juries they instruct might not do better than random guessing on a test for memory of the law.

Indeed, most of the studies demonstrating jurors' poor comprehension of the law have been simulations, performed in laboratories with mock jurors hearing (or reading) mock cases. Early studies typically relied on students to serve as jurors. Students are not representative of actual jurors in age, education, experience, or political beliefs. Although more recent studies have commonly used adult subjects who are eligible for jury service, some doubts remain about the representativeness of the samples. An actual jury is not simply 12 people called from tax, election, or motor vehicle lists: Rather, a jury consists of people selected by judges and attorneys through voir dire, a process that eliminates as many as half of all potential jurors. Few researchers have bothered with this expensive procedure. In 
terms of basic theory, and in terms of internal validity, it adds little. There is no reason to believe that the results should not apply to actual jurors; on the other hand, there is little direct evidence that they do.

Questions have also been raised about experimenters' ability to capture the atmosphere of a real trial in a laboratory setting. Certain aspects of a trial are costly, time-consuming, or simply impossible to recreate in an experiment. Actual trials include a judge, attorneys, plaintiffs, defendants, witnesses, court officers, a courtroom, deliberation chambers for the jury, unlimited deliberation time, and jury sequestration, if necessary. Simulations have ranged from extremely schematic to extremely realistic, the most realistic to date being the Hastie et al. (1983) study of the unanimity rule.

No matter how realistic the simulation, however, research ethics typically require that the subjects be aware that it is a simulation, that no one's fate actually depends on their decision. No matter how long simulated juries deliberate (Hastie et al., 1983) or how passionately they dispute the issues (Cowan, Thompson, \& Ellsworth, 1984), there is always the possibility that real juries might behave differently; thus our confidence in the generalizability of a laboratory finding is usually greatly enhanced by the demonstration of the same result in a study of real jurors. With respect to juror comprehension of the law, one might argue that a juror who is personally involved in the drama of a real trial might try harder to understand the relevant law and might, therefore, perform better than a subject in a simulation.

Finally, in most laboratory studies, the judge's instructions are the only source of the relevant law, but in real trials, the attorneys also have opportunities to communicate to the jurors about the legal rules. Few good attorneys are content to rely on the judge to transmit the law. Instead, trial manuals advise attorneys to explain the pertinent law during voir dire, during opening argument, and again during closing argument (Belli, 1954; Bailey \& Rothblatt, 1974; Imwinkelreid, 1981; see also Tanford, 1983). In real trials, it is argued, all relevant law will be described by the attorneys as well as by the judge, since in the adversarial system both sides will emphasize the information that helps their case. Thus many legal scholars believe that simulations miss the point, because any ambiguities in the judges' instructions are compensated for when the attorneys present their cases to the jury and instruct them in the law. According to Tanford (1990):

by the time the court reads the final jury charge, all important legal issues should have been explained to the jury in simplified language three times by each side [voir dire, opening statement, closing argument]. If the lawyers were minimally competent, the jury will have been alerted at the beginning to the important issues and jurors who cannot comprehend the law will have been removed. In argument, the law will have been placed in the context of the facts of the case and probably written in outline form on a chalkboard. Therefore, most of the suggestions by psycholinguists [about ways to improve juror understanding] merely duplicate what a competent trial attorney already does. (p. 105)

The purpose of this study is to test the generalizability of the laboratory demonstrations of poor juror understanding of the law by examining real jurors' ability to recognize the law in the cases they decided. Unlike the subjects in most 
simulation studies, these jurors were selected (and instructed) by attorneys during voir dire, were responsible for the fates of the people on trial, and were exposed to the full range of relevant legal information characteristic of a trial-the formal judicial instructions as well as whatever informal instruction was provided by the attorneys during voir dire and opening and closing arguments.

The design of the study allowed us to assess the jurors' comprehension of the law in several ways. First, of course, their memory of the instructions could be judged against an absolute standard of accuracy. Second, citizens who were chosen to serve on juries (and thus received instructions) could be compared to citizens who were called for jury duty but did not actually sit on a jury. Finally, we could test whether jurors who received instructions in a particular area of substantive law understood that law better than they understood other areas of law, and whether they understood that law better than jurors who had not heard those particular instructions. That is, if instructions are effective, jurors in an assault case should know the definition of assault better than the definition of delivery of controlled substances (a within-subject comparison) and better than jurors who served in drug sale cases (a between-subjects comparison). Although none of these comparisons provides a complete solution to the various problems of nonrandom assignment, convergent results from all four comparisons would greatly strengthen our confidence in their validity.

\section{METHOD}

\section{Participants}

Participants were recruited from a pool of 558 citizens who were called for jury duty for the Twenty-Second Judicial Circuit Court in Washtenaw County, Michigan, during February and March of 1989. Shortly after completing their jury service, they were mailed a questionnaire designed to test their knowledge of substantive and procedural law. Questionnaires were mailed to all those who appeared for jury duty, whether or not they actually sat on a trial. Of these people, 224 returned completed questionnaires (response rate $=40 \%$ ); 140 of those responding had served on juries $(63 \%)$.

Ninety-seven percent of the participants had high school diplomas, $53 \%$ had finished college, and $22 \%$ had graduate degrees. Age of participants ranged from 20 to 70 , with $80 \%$ between 30 and 59 , and $60 \%$ between 30 and 49 . Twenty-six percent had previous jury experience $(N=59)$. One hundred participants were male $(45 \%)$. Eighty-five percent were employed; most of the unemployed people were retired.

Jurors in Michigan are recruited from the state driver's license and Michigan Identification lists. Jury duty lasts for a month, during which those called must appear at the courthouse each Monday for the week's jury selections; if they are not selected for a jury they do not have to come back to the courthouse until the next Monday. A juror may be allowed to serve on a 1-day, one-trial basis, if he or she can show that the usual procedure would be a serious hardship. The court 
typically allows each attorney 3 peremptory challenges in civil cases, 5 in most criminal cases, and 12 in criminal cases involving a possible life sentence.

\section{Comparison Groups}

During the course of their jury duty, some served on trials; others did not. Those who served on criminal trials $(n=118)$ received procedural instructions from the judge on the evaluation of testimony and evidence, the presumption of innocence and reasonable doubt, and the factors that may and may not be considered during deliberation. Those who did not serve on a trial did not receive any instructions $(n=84)$. A third, smaller set served only on civil trials $(n=22)$, which have somewhat different procedural regulations, most notably on burden of proof. Therefore, we were able to compare those who served on criminal trials, civil trials, and no trial.

Participants who served on criminal trials were also instructed in the substantive law governing the crime(s) charged. For example, a juror for a stolen property case would have heard instructions specific to stolen property, and so forth. The majority heard cases involving drug deals ("delivery of controlled substances"; $n=63$ ), cases involving assaults ("assault with intent to cause great bodily harm," "assault with intent to murder," or "assault with a dangerous weapon"; $n=26$ ), or cases involving possession of stolen property ( $n=22)$, with the others who heard criminal cases distributed across a large variety of crimes. Thus we were able to compare participants who were instructed in a specific area of substantive law with those who were not, in terms of their knowledge of that particular body of law, and we were able to compare their knowledge of the law they had heard with their knowledge of the law governing other types of crime.

The jury instructions on substantive and procedural law are standardized throughout the state of Michigan (Michigan Criminal Jury Instructions, State Bar of Michigan, 1987). For a given crime, all judges must give the same instructions, word for word, to their juries (State Bar of Michigan, 1988). However, there is no required method for delivering these instructions. Michigan judges may, at their discretion, deliver the instructions orally only, or they may supplement their spoken instructions with a tape recorded version of the instructions, and/or a written copy. All three methods of instruction are used by the judges of the Twenty-Second Judicial Circuit. Therefore, we were able to compare jurors who received oral instructions only versus oral and taped versus oral and written instructions.

\section{The Questionnaire}

The first three pages of the 7-page questionnaire asked about the type of trial the jurors had served on (if any), the method the judge had used to deliver the instructions, and their previous experience with the law or jury duty. Jurors were also asked if they had requested additional instructions from the judge during their deliberation. The rest of the questionnaire included 29 questions about the law relevant to the various crimes. These questions consisted of one- or two-sentence 
true-false statements, with a "Don't know" option included so that subjects who knew they were ignorant could say so.

The statements were taken from the Michigan Criminal Jury Instructions (State Bar of Michigan, 1987) and followed closely the standardized wording. Occasional plain-English changes were made in order to simplify excessively legalistic passages (example: "The jury may reject the whole testimony of a witness who willfully has testified falsely about any one point" was changed to "If a witness lies about any one point the jury may decide not to believe anything the witness has said"). However, in order to assure that the statements' legal validity was preserved, we made no simplifications that changed or "clarified" the meaning of the instruction. For example, the definition of reasonable doubt, as stated in the instructions, requires that jurors possess a "moral certainty" that a crime has been committed in order to cast a guilty vote. This phrase appeared verbatim in the questionnaire, because any ambiguity is inherent in the instruction, and to remove the ambiguity would be to change the meaning.

The first ten questions concerned the procedural duties of jurors. These are instructions that all jurors in criminal trials receive, telling them how to evaluate testimony and evidence, explaining the presumption of innocence and reasonable doubt, and delineating the factors that may be considered during deliberation. Examples of these questions were: "Unless a juror is morally certain of the truth of the charge, that juror has reasonable doubt, as defined by the law" (True); "In reaching a decision, the jury may consider the consequences of their verdict" (False). These 10 questions were taken from a study by Smith (1987; Smith based her questions on California law, but all the statements are also legally correct in Michigan).

The remaining 19 questions concerned the substantive law for various types of crimes (see Table 1). Questions were developed for each of the 10 most commonly tried crimes in Washtenaw County. Examples of these questions are (a) for assault with a dangerous weapon, "If the defendant threatened the victim with a pistol which looked dangerous but was really a toy, the defendant is still guilty of assault with a dangerous weapon" (True); (b) for delivery of controlled substances, "A person who gives a bottle containing illegal drugs to another person, without knowing what is in the bottle, is not guilty of delivering a controlled substance" (True).

\section{Procedure}

On the first day of their jury duty, the clerk told the members of the panel that they would receive a questionnaire from the University of Michigan at the termination of their jury service and requested that they fill it out, though the voluntary nature of the study was emphasized. After their service was over, they received an envelope in the mail containing their paycheck, a cover letter, the questionnaire, and a postage-paid return envelope addressed to the Michigan Law School. The cover letter was on University of Michigan letterhead and explained that the study was being conducted by the university with the approval and cooperation of the Washtenaw County Circuit Court. The importance of preserving and under- 
standing the jury system was emphasized, and they were told that this was an opportunity to communicate their views.

The response rate would probably have been higher had we been able to administer the questionnaires at the courthouse, and jurors' memory for the law might have been somewhat better. However, the court administrators feared that filling out the questionnaires before jury service was completed might affect jurors' future deliberations.

A $40 \%$ response rate is not unusual for mail surveys, where response rates over 50\% are rare (Kerlinger, 1973). Our sample was somewhat unrepresentative of the pool from which it was drawn in two ways: First, $63 \%$ of our sample had actually served on a jury, as compared to $45 \%$ of the pool as a whole. (This also means that our sample included $56 \%$ of the actual jurors.) It is not surprising that the people who served on juries should be more interested in filling out the questionnaire than those who did not, and for our purposes this "unrepresentativeness" is useful, since we are primarily interested in the performance of people who actually heard the law as presented at trial, rather than in background levels of legal knowledge in the population. Second, highly educated people were somewhat overrepresented in our sample. Thus, if education is correlated with juror comprehension, our results may overestimate jurors' understanding of the law.

\section{RESULTS}

\section{Performance of the Jurors-Procedural Law}

For the 10 questions involving jurors' duties and procedural rules, jurors who heard criminal cases answered an average of 4.78 correctly, jurors who heard civil cases averaged 4.18 correct, and subjects who did not sit on a trial averaged 3.81 correct. This effect is highly significant, $F(2,221)=8.67 ; p<.0005$. Instructed jurors scored higher than those not instructed, indicating that judges' instructions on procedural law improve juror understanding. Jurors who sat on civil cases performed somewhat worse than jurors who sat on criminal cases, though the effect was of marginal significance $(p<.12)$. The difference between civil jurors and jurors who heard no trial was not significant. The intermediate performance of the civil jurors is understandable, as the procedural instructions for civil jurors coincide in part and differ in part from the criminal instructions on which the questions were based.

Jurors were more often right than wrong in their answers to questions about the impermissibility of considering the consequences of their verdict, the fact that statements made by attorneys are not evidence (criminal jurors only), their right to consider anything in determining witness credibility, their right to reject the entire testimony of a witness who lies on one point, and "moral certainty" as part of the definition of reasonable doubt (over $50 \%$ of nonjurors got this right as well). Jurors were more often wrong than right in their answers to questions about their right to ignore irrelevant instructions, the difference between direct and circumstantial evidence, the fact that the prosecution had the burden of proof (less than 
a third of those who served on criminal juries got this right), the prohibition against inferring guilt if a defendant did not testify, and their freedom to reject expert testimony.

Although the instructions significantly improved the jurors' knowledge of the procedural rules, their absolute levels of understanding were rather low; even instructed jurors got fewer than half of the questions correct. Nor were they aware of their ignorance-they very rarely chose the "I don't know" option (criminal jurors: $10 \%$ of the time; civil jurors: $11 \%$; nonjurors: $18 \%$ ).

\section{Performance of the Jurors-Substantive Law}

Tables 1 and 2 list the results for the substantive law questions. If jurors understand the instructions they hear, one would expect that those who served on a particular type of criminal case would understand the laws defining that particular crime better than other areas of criminal law. This was not the case. A comparison of columns $A$ and $B$ in Table 2 shows that criminal jurors were correct on $41 \%$ of the legal issues pertinent to the cases that they heard, and $33 \%$ of the legal issues that were irrelevant to those cases. This difference was not significant. One might also expect that they would understand the instructions better than people who had never heard those instructions. This was not the case either. Column $\mathrm{C}$ shows that $35 \%$ of the questions were answered correctly by individuals who did not hear the instructions bearing on the particular crimes, not significantly less than the $41 \%$ correct response rate by those who did hear the

Table 1. Percentage Breakdown on Substantive Law Questions

\begin{tabular}{lccc}
\hline \multicolumn{1}{c}{ Question $^{a}$} & Incorrect & Correct & Don't know \\
\hline Criminal sexual conduct: victim resistance & .08 & .60 & .32 \\
Criminal sexual conduct: victim free to leave & .40 & .17 & .43 \\
Stolen property: knowledge & .38 & .24 & .38 \\
Stolen property: value of property & .03 & .54 & .43 \\
Assault with intent to murder: intent to kill & .54 & .16 & .30 \\
Assault with intent to murder: premeditation & .04 & .73 & .23 \\
Assault with intent less than murder: intent & .44 & .26 & .30 \\
Assault with intent less than murder: no injury & .18 & .50 & .33 \\
Assault with a deadly weapon: no injury & .05 & .72 & .23 \\
Assault with a deadly weapon: toy gun & .04 & .61 & .35 \\
Armed Robbery: victim no property & .73 & .06 & .21 \\
Armed Robbery: gun not used & .55 & .17 & .29 \\
Manufacturing a controlled substance: personal use & .74 & .07 & .19 \\
Manufacturing a controlled substance: relabel bottle & .18 & .22 & .59 \\
Delivery of a controlled substance: knowledge & .43 & .17 & .40 \\
Operating under the influence: blood alcohol level & .18 & .46 & .36 \\
Operating under the influence: no physical impairment & .03 & .75 & .22 \\
Operating while intoxicated: loss of control & .19 & .41 & .41 \\
Operating while intoxicated: blood alcohol level & .33 & .26 & .41 \\
Total & .30 & .37 & .34 \\
\hline
\end{tabular}

${ }^{a} N=224$ for each question. 
Table 2. Percent Correct on Substantive Law Questions by Instructed Versus Uninstructed Jurors

\begin{tabular}{|c|c|c|c|c|}
\hline \multirow[b]{2}{*}{$\begin{array}{c}\text { Jurors } \\
\text { instructed for }\end{array}$} & \multirow[b]{2}{*}{$N^{a}$} & \multicolumn{2}{|c|}{ Instructed jurors } & \multirow{2}{*}{$\begin{array}{c}\text { Uninstructed jurors } \\
\text { C. Baseline for } \\
\text { instructed questions }\end{array}$} \\
\hline & & $\begin{array}{l}\text { A. Instructed } \\
\text { questions }\end{array}$ & $\begin{array}{l}\text { B. Other } \\
\text { questions }\end{array}$ & \\
\hline Stolen property & 22 & .34 & .35 & .39 \\
\hline $\begin{array}{l}\text { Assault with intent to } \\
\text { murder }\end{array}$ & 5 & .40 & .29 & .45 \\
\hline $\begin{array}{l}\text { Assault with intent } \\
\text { less than murder }\end{array}$ & 11 & .59 & .40 & .36 \\
\hline $\begin{array}{l}\text { Assault with dangerous } \\
\text { weapon }\end{array}$ & 10 & .70 & .26 & .66 \\
\hline Armed Robbery & 9 & .17 & .27 & .11 \\
\hline $\begin{array}{l}\text { Delivery of controlled } \\
\text { substances }\end{array}$ & 63 & .25 & .38 & .14 \\
\hline Total & 120 & .41 & .33 & .35 \\
\hline
\end{tabular}

Note. An individual may have answered questions about more than one crime, either through serving on more than one trial, or through hearing instructions on different possible verdicts in the same trial (e.g., lesser included offenses).

${ }^{a}$ This figure represents the number of jurors who received each type of instruction.

instructions. Thus both within-subjects and between-subjects analyses suggest that the law as communicated in trials is not well understood by jurors. ${ }^{1}$

Another way to examine the results of the substantive law questions is to examine each question individually. There were six crimes for which five or more jurors were instructed. For only two of these crimes (assault with intent to do great bodily harm less than murder and delivery of controlled substances) did instructed jurors score higher than 10\% over uninstructed subjects (additionally, subjects scored higher on their instructed questions than on their uninstructed questions for only three of the six crimes, but this may be an effect of comparing across questions of varying difficulty). For three of the individual questions (one

\footnotetext{
${ }^{1}$ Our statement that jurors should understand the law they heard better than the law they did not hear would be true in the case of perfectly effective instructions. Obviously the instructions were far from perfectly effective, so the situation is more complicated: The laws relating to some crimes were inherently more difficult to understand with or without instructions. For some crimes, correct responding was over $50 \%$; for others, it was below $25 \%$. Thus jurors may not understand the law they heard better than the law they did not hear, if they happened to hear instructions on an especially difficult law. The comparison between instructed and uninstructed jurors becomes particularly important in this context. Even this comparison, however, may be affected by instruction difficulty. If there were more jurors who served in trials with "difficult" instructions than in trials with "easy" instructions, the overall effect of instructions might be artificially depressed. The percentages at the bottom of Table 2 are unweighted means of the six percentages above. Were the individual percentages to be weighted according to the number of jurors hearing each instruction, the overall means might be higher or lower than the unweighted values, thus making the jurors appear somewhat more or somewhat less competent. Weighting the percentages in Column A according to the number of jurors hearing each instruction results in an overall mean of .34 . Weighting the values in Column $\mathrm{C}$ by $n$ results in an overall mean of .26 . Thus, regardless of how the individual percentages are combined, absolute levels of performance are low, and the difference between instructed and uninstructed jurors is small.
} 
on delivery of controlled substances and two on stolen property), there were enough respondents to perform chi-square analyses comparing the responses of instructed jurors to jurors who served on other trials. Instructed jurors performed significantly better on the delivery of controlled substance question than did jurors serving on other trials, $\chi^{2}(1, N=224)=3.89 ; p<.05$, but neither of the other two questions showed significant differences.

\section{Instruction Type}

Of the 118 jurors who served on a criminal trial, 67 received oral instructions only, 42 received oral and tape-recorded instructions, and 9 received oral and written instructions. For purposes of analysis, jurors were grouped into oral instructions only $(n=67)$ and augmented instruction (tape or written; $n=51$ ) groups. These two groups did not differ in the number of procedural law questions answered correctly $\left(M^{\prime} \mathrm{s}=4.70,4.78\right)$ or in the percentage of substantive law questions (for which they received instructions) answered correctly ( $M$ 's $=.35$, $.40)$.

\section{Requesting Help from the Judge}

Thirty-two jurors indicated that their jury had requested help from the judge during their deliberation; only one received no response. In most cases, they had asked for clarification of the criminal law. Some heard the judge repeat the previous instructions, some heard a tape recording, some received a written copy of the instructions from the judge, and some had the judge explain the statutes in simpler words. However, all of these jurors had in common the fact that they both requested and received help from the judge. These jurors did not score significantly differently from other jurors on the procedural law. However, for questions about substantive law on which they were instructed, those who requested help were correct $54 \%$ of the time, whereas the jurors who were instructed but did not ask for help were correct $31 \%$ of the time (see Table 3 ); this difference was highly significant, $\left.\chi^{2}(1, N=187)=8.61, p<.01\right)$.

In order to discover which type of assistance was most useful to the jurors, participants who had requested help were classified by the type of response they got. Two categories were created-jurors who returned to the courtroom and simply listened to the same instructions again (in spoken or tape recorded form), and jurors who received instructions in a new form (either they received a written copy of the instructions to take with them into the jury room, or the judge explained the statutes in his or her own words). The jurors who received additional

Table 3. Percentage Breakdown for Criminal Jurors on Questions Specific to the Instructions Received by “Asked Judge" Condition

\begin{tabular}{ccccc}
\hline Asked judge? & $\begin{array}{c}\text { Number of } \\
\text { questions }\end{array}$ & Incorrect & Correct & Don't know \\
\hline Yes & 51 & .26 & .54 & .20 \\
No & 133 & .38 & .31 & .32 \\
\hline
\end{tabular}


information from the judge were correct on $67 \%$ of the substantive law instructions for which they were instructed $(N=21$ questions), while those who simply heard a repetition of the instructions were correct $45 \%$ of the time $(N=33$ questions). Although these groups are too small for reliable statistical analysis, the data are suggestive. Simply hearing the instructions repeated improved understanding (14\% over the jurors who did not receive help), but receiving supplemental information from the judge, be it a written copy of the instructions or a description in less complicated terms, seemed to improve understanding even more ( $36 \%$ over the jurors who did not receive help).

\section{Background Factors}

The data were examined to see whether age, previous experience on juries, education, or gender were predictors of performance. Two-way cross tabulations were performed on each demographic variable for both procedural and substantive law questions. No significant effects were found due to age or previous jury experience. Education had no effect, except that the 5 participants who had law degrees all scored approximately $20 \%$ higher than the average. Gender did not predict knowledge of procedural law, but men were correct $40 \%$ of the time on the substantive law questions, whereas women were correct $35 \%$ of the time. This difference was significant, $t(222)=2.11, p<.05$; however, after removing the lawyers from the sample (four of the five lawyers were male), and participants who did not indicate their education level, the gender difference was only marginally significant, $t(206)=1.73 ; p=.08 .^{2}$

Analyses of covariance were performed to determine whether any of these factors affected the results previously obtained. After controlling for these variables, the differences between instructed and uninstructed jurors' performance on procedural law questions were still significant, $F=(2,202)=7.07, p<.002$, and all other tests remained insignificant.

\section{DISCUSSION}

Overall, jurors' understanding of the judges' instructions was far from complete; they responded correctly to questions of law less than half the time. However, some procedural conditions were found to have a significant effect on juror performance. Judges' instructions significantly improved performance on questions about the procedural law, but instructions had no effect on jurors' knowledge of the substantive law they were supposed to apply. The procedural law

\footnotetext{
${ }^{2}$ For statistical purposes, it should be noted that in the latter sample the variance among women (12.05) was much greater than the variance for men $(8.61)$; this was a significant difference, $F(113,93)$ $=1.40 ; p<.05$. Women's scores had more outlying data points at both ends of the distribution curve than did men's scores. Because it is an assumption of a $t$ test that the variances are similar, caution should be used when evaluating the statistics on gender differences.
} 
instructions, though effectively raising jurors' knowledge above baseline levels, failed to raise it to a level desirable for fair and meaningful deliberation. Jurors who requested help from the judge scored significantly higher than other jurors when tested for recall of judges' instructions. Written or plain-English responses from the judges in response to requests for help seemed to improve performance more than a simple reiteration of previous instructions.

Our results also indicate that the idea that the attorneys resolve ambiguities of the pattern instructions may reflect the ideal attorney performance described in trial manuals rather than the actual behavior of most attorneys in most real trials. This ideal is very likely a fiction in most cases. First, it may not occur to the attorneys to mention more than one or two obvious points of law, such as the reasonable doubt standard (for criminal defense lawyers). In consulting with trial lawyers, one of us has often been faced with blank stares when she suggested that voir dire and closing argument should educate the jurors about the law. Second, the attorneys may be unevenly matched, so that only the law favorable to one side is clarified. Third, points of law that neither side considers particularly advantageous may go unmentioned. If the prosecutor is charging first degree murder and the defense attorney is arguing for self defense, who is going to explain the difficult concepts of second-degree murder and manslaughter, even though these may be the most likely verdicts?

Jurors who received written or tape-recorded instructions did not perform better than those who received only oral instructions. Although these results are counterintuitive, they are consistent with the meager body of previous research (Hastie, 1983; Heuer \& Penrod, 1989). A useful next step might be a deliberation study in which subjects' actual use of the written or taped instructions is examined.

A new finding of this study is that jurors who requested help from the judge performed substantially better than those subjects who did not. When the judge responded by providing supplemental information, either in the form of written instructions or by explaining the instructions in their own words, the jurors' understanding of the instructions reached fairly high levels (up to 67\%).

Unfortunately, comments we received on the questionnaires indicated that judges do not always encourage jurors to ask questions, and that judges' demeanor in the courtroom is often intimidating, making jurors reluctant to interrupt the proceedings. One participant, a 34-year-old who had finished some college, felt that the judge "just wanted us to reach a decision. He seemed worried that there would be a hung jury when we asked for more instructions." A 38-year-old participant with a high school diploma said that after asking for additional information about the instructions for tax fraud, "We were told that we were responsible for deciding appropriate definitions of terms in tax law. We felt adrift and being [sic] in a position of making law instead of applying it." Since our results indicate that jurors who receive help perform significantly better than those who muddle through, we would recommend that jurors be informed that they may ask questions and encouraged to do so. Additionally, further research in this area would be desirable, in order to confirm this finding and examine in greater detail the dynamics of asking the judge for assistance. 


\section{Some Methodological Considerations}

Of course it is possible that our questionnaire was exceptionally difficult. However, all our questions were based on the very jury instructions that were given in court, with some plain-English changes made in an attempt to enhance participants' understanding. Despite our efforts, some subjects commented that they thought the questionnaire was difficult, imposing, or vague. The majority of these participants were well-educated people who expressed frustration, no doubt because they were unaccustomed to having difficulty with written material. Ironically, hostility was usually directed at the experimenters and not at the actual instructions from which the taxing questions were taken. A 24-year-old college graduate commented, "This is really a joke! Maybe ask the questions in laymen's terms. I'm hardly sure of some of these answers. But you U-M lawyers probably like to make the average citizen feel 'dumb.' I, too, have a degree-but I'm not stuffing it in others' faces!' Another participant, a 23-year-old college graduate, wrote a long memo on the back of her questionnaire which began as follows, "I am a copy editor for a major magazine. As a defender of clear and meaningful prose, I feel compelled to correct some of the language in your questionnaire." Clearly, many participants disliked the wording of the questions, but few recognized that the language was the same as they had heard in court.

Given the less-than-perfect response rate, it is also possible that the results reflect a skewed sample. Though the participants performed poorly on most tasks, it seems unlikely that the sample was systematically biased toward those who were most ignorant, inattentive, or uninterested. Rather, one would expect that those who returned the survey were the people most interested in juries and the law, and possibly most knowledgeable. In fact, if the participant pool was unrepresentative, it was because it tended to favor the well-educated.

Finally, because we did not communicate with our respondents until after they had completed their month of jury service, the data from this study, standing alone, could reflect poor recall of the judge's instructions rather than poor comprehension. It is conceivable that real jurors understand the instructions well when they hear them, but forget them once their jury service is over. We feel that this interpretation is unlikely, because our findings do not stand alone. Given the numerous laboratory studies that have demonstrated poor comprehension on immediate posttest measures, the parsimonious explanation is that the poor performance of our jurors reflects the same disability, rather than a different one.

\section{Further Questions and Implications}

Our aim in this study was to discover whether the poor understanding of the law repeatedly shown by subjects in jury simulation studies generalizes to real jurors sitting on real cases. The answer is clearly yes. The amount of supplementary instruction given by the attorneys in our study did not dramatically improve juror comprehension over the dismal levels found in laboratory studies. Our study does not address the question of the potential effectiveness of attorney instruction-that is, we cannot tell whether our jurors were exposed to frequent repeti- 
tions of important instructions and still missed the point, or whether the attorneys failed to take advantage of their opportunity to communicate the law. Probably attorney performance was quite variable.

One might approach this question by counting the number of times various legal points were mentioned in the course of actual trials to discover whether frequency of repetition correlates with juror performance. Given the wide variability in types of case, and the ambiguities inherent in trying to code the accuracy of the attorney's attempts to communicate the law, it would be very difficult to "score" attorneys' communication of the law during an actual trial. Also, in order to control for type of case and judicial instructional style, a very large number of trials would have to be observed. A better method for answering this question would be to conduct further experimental studies, in which systematic variation of attorney techniques could provide useful information on how lawyers might improve juror comprehension.

We have shown that jurors' performance is low in an absolute sense, in that it falls far short of perfection, but we have not discussed that performance relative to anyone else's. What base line is appropriate in evaluating our claim that juror comprehension is low? Could anyone do better?

We feel that the fact that jurors are unable to understand half the instructions they are supposed to apply is a serious cause for concern regardless of what a realistic base line might be. There are, however, some glimmers of information in our data suggesting that better comprehension is possible. Two of the lawyers in our sample actually served on juries. Their performance was better than that of the lay jurors ( $70 \%$ correct) and better than that of the uninstructed lawyers. Although they did better than other jurors, they too fell rather short of perfect performance, suggesting first, that $100 \%$ accuracy may be an unrealistic assumption, and second, that the problem is not simply a function of the incompetence of lay jurors, but of the current methods of jury instruction.

Also, jurors who asked for clarification and got it performed better than the others, substantially so when they received more than a simple reiteration. Thus while $100 \%$ performance may (or may not) be out of reach, considerable improvement over the $40 \%$ level seems an eminently realistic goal.

Does it matter? Do legal policymakers care about the effective communication of legal instructions to the jury? An enormous proportion of appellate court decisions involve errors in instruction. Every day cases that have gone through months or years of preparation and litigation are reversed because the judge failed to state the law with exact accuracy. Jury instructions are constantly being rewritten to reflect more precisely the nuances of the law, but legal policymakers and courts rarely concern themselves with jurors' comprehension of the law. Unless some attention is paid to the jurors' use of the instructions they are given, the never-ending, intensive solicitude for the wording of the law is pedantry in fantasyland: The law as spoken by the judge is of the utmost consequence; the law as understood by the jurors, moments later, is not a matter of concern. Either this implies the assumption that the jurors do understand what the judge says, or it implies that judicial instructions are magical incantations, in which the perfect utterance is not a means to understanding but an end in itself. 


\section{REFERENCES}

Bailey, F. L., \& Rothblatt, H. (1974). Fundamentals of criminal advocacy, New York: The Lawyers Co-operative.

Belli, M. (1954). Modern trials. Indianapolis: Bobbs-Merrill.

Charrow, R. P., \& Charrow, V. (1979). Making legal language understandable: A psycholinguistic study of jury instructions. Columbia Law Review, 79, 1306-1374.

City of Los Angeles v. Heller, 475 U.S. 796 (1986).

Cowan, C. L., Thompson, W. C., \& Ellsworth, P. C. (1984). The effects of death qualification on jurors' predisposition to convict and on the quality of deliberation. Law and Human Behavior, 8 , 53-79.

Ellsworth, P. C. (1989). Are twelve heads better than one? Law and Contemporary Problems, 52, 205-224.

Ellsworth, P. C., \& Getman, J. G. (1987). The use of social science in legal decision making. In L. Lipson \& S. Wheeler (Eds.), Law and the social sciences (pp. 581-636). New York: Russell Sage.

Elwork, A., Sales, B. D., \& Alfini, J. J. (1977). Juridic decisions: In ignorance of the law or in light of it? Law and Human Behavior, 1, 163-589.

Elwork, A., Sales, B. D., \& Alfini, J. J. (1982). Making jury instructions understandable. Charlottesville, VA: Michie.

Forston, R. F. (1975). Sense and non-sense: Jury trial communication. Brigham Young University Law Review, 601-637.

Hastie, R. (1983). Final report to the National Institute for Law Enforcement and Criminal Justice. Unpublished manuscript, Northwestern University.

Hastie, R., Penrod, S. D., \& Pennington, N. (1983). Inside the jury. Cambridge: Harvard University Press.

Heuer, L., \& Penrod, S. D. (1989). Instructing jurors: A field experiment with written and preliminary instructions. Law and Human Behavior, 13, 409-430.

Imwinkelreid, E. (1981). Handbook for the trial of contract lawsuits: Strategies and techniques. Englewood Cliffs, NJ: Prentice-Hall.

Kaplan, M. F., \& Kemmerick, G. D. (1974). Juror judgment as information integration: Combining evidential and nonevidential information. Journal of Personality and Social Psychology, 30, 493499.

Kassin, S. M., \& Wrightsman, L. S. (1979). On the requirements of proof: The timing of judicial instruction and mock juror verdicts. Journal of Personality and Social Psychology, 37, 1877-1887.

Kerlinger, F. N. (1973). Foundations of behavioral research (2nd. Edition). New York: Holt, Rinehart \& Winston.

Kerr, N., Atkin, R., Stasser, G., Meek, D., Holt, R., \& Davis, J. (1976). Guilt beyond a reasonable doubt: Effects of concept definition and assigned decision rule on the judgments of mock jurors. Journal of Personality and Social Psychology, 34, 282-294.

Martin v. Ohio, 480 U.S. 228 (1987).

Parker v. Randolph, 442 U.S. 62 (1979).

Richardson v. Marsh, 481 U.S. 200 (1987).

Sand, L. B., \& Reiss, S. A. (1985). A report on seven experiments conducted by District Court judges in the Second Circuit. New York University Law Review, 60, 423-497.

Severance, L. J., \& Loftus, E. F. (1982). Improving the ability of jurors to comprehend and apply criminal jury instructions. Law and Society Review, 17, 153-198.

Smith, V. L. (1987). The psychological and legal implications of pre-trial instruction in the law. Unpublished dissertation, Stanford University.

State Bar of Michigan, Special Committee on Standard Criminal Jury Instructions. (1987). Michigan criminal jury instructions. Ann Arbor, MI: The Institute of Continuing Legal Education.

State Bar of Michigan. (1988). Michigan rules of court. St. Paul, MN: West.

Tanford, J. A. (1983). The trial process. Law, tactics, and ethics. Charlottesville, VA: Michie.

Tanford, J. A. (1990). The law and psychology of jury instructions. Nebraska Law Review, 69, 71-111.

Tanford, J. A. (1991). Law reform by courts, legislatures, and commissions following empirical research on jury instructions. Law and Society Review, 25, 155-175.

United States v. Lane, 474 U.S. 438 (1986). 